\title{
ZULLY MURILLO, CANTADORA DE MUCHAS ORILLAS
}

Entrevista

\section{Alejandro Tobón Restrepo}

Universidad de Antioquia / alejandro.tobon@udea.edu.co

Doctor en Historia de América Latina, magíster en Estudios Latinoamericanos y licenciado en Educación Musical. Docente de Música de la Facultad de Artes de la Universidad de Antioquia. Coordinador del grupo de investigación "Valores musicales regionales" de la misma universidad.

\section{Federico Ochoa Escobar}

\section{Universidad EAFIT / fedefedeochoa@gmail.com}

Magíster en Antropología con pregrado en saxofón y miembro del grupo de investigación "Valores musicales regionales" de la Universidad de Antioquia. Docente del énfasis de jazz en la Universidad EAFIT. 
Tobón, A. Ochoa, F. (2015) Zully Murillo, cantadora de muchas orillas. Calle14, 11 (16) pp. 94 - 107

\section{ZULLY MURILLO, CANTADORA DE MUCHAS ORILLAS}

\section{RESUMEN}

Zully Murillo, cantadora tradicional del Atrato, compositora y mujer de vanguardia, recrea a través de esta entrevista la cotidianidad de su vida, desde su niñez hasta la edad adulta, en un viaje de la memoria donde es posible leer la cultura del Pacífico colombiano de los últimos 70 años. La vida del río, la música de las orillas, los rituales y las fiestas, los romances y alabaos, la educación secundaria, la docencia, la creación e interpretación musical, y la música como eje de su vida son los principales temas que se abordan en este diálogo.

\section{PALABRAS CLAVES}

Músicas del Pacífico, músicas tradicionales de Colombia, músicas del Chocó, músicas del Atrato, cantadoras, cantautoras, romances, alabaos.

\section{ZULLY MURILLO, IACU PATAPI VIRSIADUR}

\section{SUGLLAPI}

Virsiadura Zully Murillo Nugpatamanda Paikikin iuiarispa willa imasami pai iachaikurka uchullamandata atun kankuna chasa wiñarka atun kankuna chasa wiñarla atun iaku patapata imasa Colombiano 70 watakuna chara kawsagta iakumanda parlu patapata virsiaskamanda imasa iuiarispa virsiagta.

\section{IMA SUTI RIMAI SIMI:}

Virsiai, piciticopi, ñugpamanda, virsiaikuna Colombiamanta chocomanta virsiaikuna atratomanta virsiagkuna, kuri warmi.

\section{ZULLY MURILLO, CANTADORA OF MANY RIVERSIDES}

\section{ABSTRACT}

Zully Murillo, traditional folksinger (cantadora) of the Atrato river, songwriter and woman at the forefront, has recreated in this interview the everyday of her life, from childhood to adulthood, in a journey of the memory where the culture of the Pacific region of Colombia during the last 70 years is also to be witnessed. River life, the music of the riversides, rituals and feasts, romances and alabaos, secondary education, teaching, creating and performing music, and music as the centerpiece of her life are the main topics covered in this dialogue.

\section{KEYWORDS}

Music of the Pacific Ocean, traditional music of Colombia, music of Choco, music of the Atrato river, singers, songwriters, romances, alabaos.

\section{ZULLY MURILLO, CHANTEUSE DE PLUSIEURS RIVES}

\section{RÉSUMÉ}

Zully Murillo, chanteuse traditionnelle de l'Atrato, compositrice et femme d'avant-garde, recrée à travers cette entrevue le quotidien de sa vie, depuis son enfance jusqu'à l'âge adulte, dans un voyage de la mémoire où il est possible de lire la culture du Pacifique colombien des 70 dernières années. La vie de la rivière, la musique des rives, les cérémonials et les festivités, les musiques romantiques et les louanges, l'éducation secondaire, l'enseignement, la création et l'interprétation musicale, et la musique comme axe de sa vie sont les principaux sujets qui sont abordés dans ce dialogue. 


\section{MOTS CLÉS}

Musiques du Pacifique, musiques traditionnelles de Colombie, musiques de l'Atrato, chanteuses, musiques romantiques, louanges.

\section{ZULLY MURILLO, FOLKSINGER DE MUITAS BEIRAS}

\section{RESUMO}

Zully Murillo, folksinger tradicional do Atrato, compositora e mulher vanguarda, recriado através desta entrevista a rotina da sua vida, desde a infância até a idade adulta, uma jornada de memória onde é possivel ler a cultura do Pacífico colombiano nos últimos 70 anos. Vida do rio, a música dos bancos, rituais e festas, romances e alabaos, ensino médio, ensino, criando e executando a música, e a música como a peça central de sua vida são os principais temas abordados neste diálogo.

\section{PALAVRAS CHAVES}

Música Pacífico, música tradicional da Colômbia, Música do Chocó, Música dos Atrato, cantores, compositores, romances, alabaos.

Recibido 12/08/2014

Aceptado 10/10/2014

DOl: http://dx.doi.org/10.14483/udistrital.jour.c14.2015.2.a08 
Los primeros días del mes de diciembre de 2013, en desarrollo de la investigación "El río que baja cantando: Análisis etnomusicológico del componente sonoro de los romances de tradición oral del Atrato medio", proyecto financiado por Colciencias y la Universidad de Antioquia, miembros del grupo de investigación "Valores musicales regionales" de la Facultad de Artes de la misma universidad viajamos a la ciudad de Cali a registrar, en la voz de Zully Murillo, cantadora y compositora quibdoseña, antiguos cantos que pudieran enmarcarse en el término "romance". Buscábamos, además, completar un número significativo de textos y melodías inconclusos, recolectados en trabajos anteriores.

Ya lo esperábamos y, no obstante, nos asombramos con la calidad humana, la sonrisa, la voz, la memoria, la profundidad de una mujer que sabe contar y cantar la historia de su pueblo, relato que no es diferente a su propia historia. Zully nos abrió no solo las puertas de su casa, también la puerta de su corazón, y entre relatos y canciones nos dejó esta entrevista que por su valor cultural queremos compartir con ustedes.

Se respetó el lenguaje coloquial, cotidiano, fruto de una conversación familiar, cercana y tranquila; lenguaje desde el cual se hace visible la naturalidad y chocoanidad de esta cantadora.

\section{Familia y primera infancia: Recogiendo en las orillas}

\section{Alejandro Tobón: Zully, Contanos dónde y cuándo naciste.}

Zully Murillo: Para mí el tiempo no importa, el tiempo tiene un valor de eternidad y estamos en un segmento, en un intervalo en el cual tenemos que ver cómo encajamos en el transcurrir de la humanidad. Nací en Quibdó el 23 de abril de 1944, he vivido una vida sana, espiritualmente, rodeada siempre de afecto. Fui la primera hija, primera nieta, sobrina, hermana, la primera en todo [sonríe] y por supuesto fui apoyada por toda mi familia; [estuve] rodeada de mucho amor, me inculcaron un amplio sentido de la responsabilidad: Conmigo no necesitaron usar el castigo, todo fue siempre estímulos, y lo bueno que se logre de mí es estimulándome positivamente, nunca a las malas, porque así no sé reaccionar.

Aunque nací en Quibdó, tengo distintas procedencias. Mi papá era de Tadó, que queda en el San Juan. Su mamá, mi abuela, procedía del Valle del Cauca. Mi mamá nació en Quibdó, pero su parte materna venía del Andágueda, de Bagadó, y la paterna era de Yuto, provenientes de Frontino (Antioquia). Mi papá trabajó mucho tiempo en la Costa Pacífica, en Nuquí, también en el medio Atrato en Bojayá, en Istmina en el río San Juan. Mi mamá, siendo maestra, recorría muchos puntos, caseríos del Atrato, porque en esos tiempos de la violencia liberal-conservadora a las maestras que se habían graduado no las ponían a trabajar en el casco urbano de Quibdó sino que las mandaban -tal vez para que no aceptaran o para desterrarlasa los rincones más apartados; es decir, estuvimos regados por todo el departamento, bien sea [las cuencas del] San Juan o del Atrato, [el litoral del] Pacífico [...] y de todos esos lugares yo recibía vivencias y aportes para mi formación. Pero la verdad es que de donde más recibí y en donde creo que me formé realmente como persona y como amante de la música fue en un caserío en donde mi mamá trabajó a finales de los años 40 llamado Bocas de Tanando. Allí aprendí a conocer las costumbres, los pescadores, los curanderos, y todas sus vivencias, sus manifestaciones, enfrentados a la muerte... sus jolgorios, sus matrimonios, sus celebraciones y sus duelos; allá transcurrió mi primera infancia, etapa que es tan importante porque ahí nació mi pasión [...] Por eso creo que soy melancólica, la nostalgia de estar lejos de Quibdó metida en ese entorno tan pequeño, escuchando la algarabía de las fiestas, de los matrimonios con la pólvora, los voladores que tiraban celebrando cuando venían con las parejas, con los santos, y así mismo los alabaos y los cánticos de cuando había duelo, cuando había muerto, así que conozco bastante sobre esa parte. Mis amiguitos eran los alumnos de la escuela donde mi mamá enseñaba; en un solo salón les dictaba clase a todos los grados preparándolos para que fueran a hacer quinto de primaria a Quibdó y luego de allí siguieran como profesionales, pero esos niños que eran mis compañeros, también fueron mis maestros porque me enseñaban todos los misterios, las apariciones, las canciones, los secretos...

\section{A: Zully, ¿cómo se llamaba tu mamá?}

Z: Leonor Londoño, y mi papá Américo Murillo. Mi abuela del Andágueda se llamaba Mélida Machado Campaña, se apellidaba Campaña porque a uno de sus antepasados le tocó luchar en las guerras de fin de siglo. La familia de mi papá era del San Juan, de Tadó. Mi papá nació a Orillas de una quebrada llamada La Colorada, porque a mi abuela, Rafaela Copete que era minera, ese día la cogió el aguacero cuando se le presentaron los dolores de parto y se tuvieron que guarecer en un cambuche que hicieron y allá nació mi papá. Mi abuelo paterno era de Tadó, ellos negociaban con oro; el oro que sacaban lo vendían o lo cambiaban, y mi abuelo materno era de la parte de Samurindó-La Vuelta; por eso pienso que yo puedo recoger en mí mucho de lo que es el quehacer de todo el departamento del Chocó.

Mi papá fue juez, tinterillo, porque no tuvo la formación, no tuvo la oportunidad de ir a estudiar a la Universidad de Antioquia que era a donde iban los que podían estudiar. Mi papá trabajó en Bojayá, Nuquí, Istmina... Cuando trabajó en Quibdó, empezó su carrera como secretario, fue secretario de Gabriel Meluk Aluma, quien fue mi padrino. Mi papá era un hombre muy inteligente, leía mucho, fue el mejor estudiante que había en su colegio, y dicen los abogados que cuando ellos llegaban graduados, a él le tocaba enseñarles cómo se hacían los memoriales. 
Ese era mi papá: Sagaz, leído, cantador y compositor, y mi mamá pues no se le quedaba atrás, ella vivía y se mimetizaba con la gente.

A: Zully, tu papá estuvo en distintos sitios, tu mamá fue maestra en distintos lugares, ¿con quién vivías vos, con tu mamá o con tu papá?

Z: Donde estuvo mi mamá allá iba yo, pegadita de ella, y por eso muchas de mis canciones tienen algo que ver con ella. Entre nosotros, en nuestra cultura de los africanos, la mamá tiene el lugar preponderante en la formación de los hijos, ella es la que responde. El papá está como autoridad pero ella es la que está pendiente de todo, ella es la que regaña; el papá aprueba, desaprueba, da los permisos, pero la mamá es la que está allí conviviendo y resolviendo. Si hay que cortar leña, es la mamá la que resuelve coger un hacha, entonces yo me quedé con esa parte en que siempre vi a la mamá, pero el papá, aunque estuvo viajando, no faltaba nunca en las principales fiestas.

Ya cuando se vio un poco el cambio en la política se logró que mi mamá pudiera quedarse en Quibdó y ahí yo empecé a hacer mi educación primaria. Ahí ya traía todo el bagaje de lo que había recogido de las orillas, de cómo alguna vez casi me ahogo, del Mohán ${ }^{1}$ que salía, del pez mero que asustaba en las quebradas, de los oficios de la minería, de cuando se metían a sacar oro, de los pescadores cuando roncaba el dentón ${ }^{2}$, o se levantaban a coponear ${ }^{3} \ldots$ Mis hermanos y yo -que fuimos ocho, ahora somos siete- crecimos en medio de unas personas súper especiales que amaban la música, que cantaban en dúo [...] cantábamos en familia, porque era muy lindo ver que mientras la mamá hacía los oficios cantando, el papá estaba al lado haciéndole la voz segunda, canciones románticas o canciones antiguas, canciones que se pierden en la memoria de la gente. Por ellos yo sé muchas canciones de esas de los años 50, de los 40, hasta de los 30 [del siglo XX]. Mi madre sabía los tangos de Gardel... después yo vi las películas en Bogotá, pero ya sabía sus tangos porque ella me narraba las películas; me despertaba, me alimentaba la fantasía; ella y mi papá cantando las canciones, mis tíos y todos en la familia. De hecho tengo hermanos que tienen la vena de la música.

\section{A: ¿Y componen también?}

Z: Por supuesto. Alexis Murillo con Los Nemus del Pacífico, mi hermano se dedicaba al son montuno. Él tiene una particularidad que yo también tengo: Canta los sones como nadie los canta porque alarga una frase, la acorta, y luego coge otra y la recorta, yo no sé qué es lo que hace con esa música $[\ldots]^{4}$. Mi hermana Leonor, la que vive en San Andrés, la mamá de Buxxi5, ella es la que me siguió la cuerda porque fue mi alumna, y dice que yo le enseñé a tocar guitarra, y lo que hice fue: "Mi papá me enseñó que esto era Do y no sé qué, y aquí cambiamos y tal", ella canta sus canciones y se acompaña con guitarra. Me seguía en los coros, las danzas, me ayudaba a recolectar información de las canciones que traían las señoras de las orillas de los ríos, me enriquecía y me enriquece aún, porque... no me siento bien si ella no me está ayudando en los coros

A: Es decir, ¿para vos esa música sin los coros está incompleta?

Z: Sí. Yo oí los alabaos y todos tienen que tener el "Salve Regina, Dios te salve palabra divina", y oigo lo que tienen que repetir, y en los estribillos de las canciones del Chocó está presente el coro. Además están mi hermano Américo, que también ha sido cantante de La Contundencia ${ }^{6}$, él vive en Quibdó, es abogado; él fue el que estuvo siempre con Tufik y con Antero Agualimpia en los cánticos y en las danzas, al igual que Alexis. Y mi hermano Nicolás, que vive en Bogotá y que también tiene su grupo. En mi familia les gusta mucho la percusión: Bombos y platillos. Algunos de mis tíos tocaban clarinete. Mi papá cuando estaba joven era de la banda de Tadó, tocaba pícolo. Otro tío tocaba trompeta, así que hemos estado rodeados de música.

A: ¿Tu adolescencia, tu primera juventud la pasaste también en Quibdó?

Z: Sí, estudié en las escuelas públicas, me gradué en secundaria normalista, maestra superior. Pero mis padres ya tenían otra mentalidad, no querían que yo me fuera a quedar solamente de maestra [normalista], me mandaron a Bogotá a estudiar a la Pedagógica en donde terminé licenciatura en matemáticas y física, y después de estudiar en Bogotá

1. Mito de características antropofágicas, cuyo medio de vida es el monte.

2. Se refiere al sonido que hace este pez en el agua, sonido que parece un ronquido.

3. Usar el copón. Canasta larga hecha de astillas de madera amarrados con bejucos para pescar.

4. Téngase en cuenta que el "son chocoano", de innegable ascendencia en el son cubano, es producto del intercambio con el Caribe que el Atrato permitía.

5. Buxxi es un reconocido productor, compositor y cantante de reggaetón y dancehall.

6. Chirimía chocoana, originaria de Quibdó. Dirigida por Leonidas Valencia, "Hinchao". Forma parte de la ola musical que añadió otros instrumentos a las bandas tradicionales para crear un estilo más de orquesta.

Atrato. Fotografía: Alejandro Tobón 

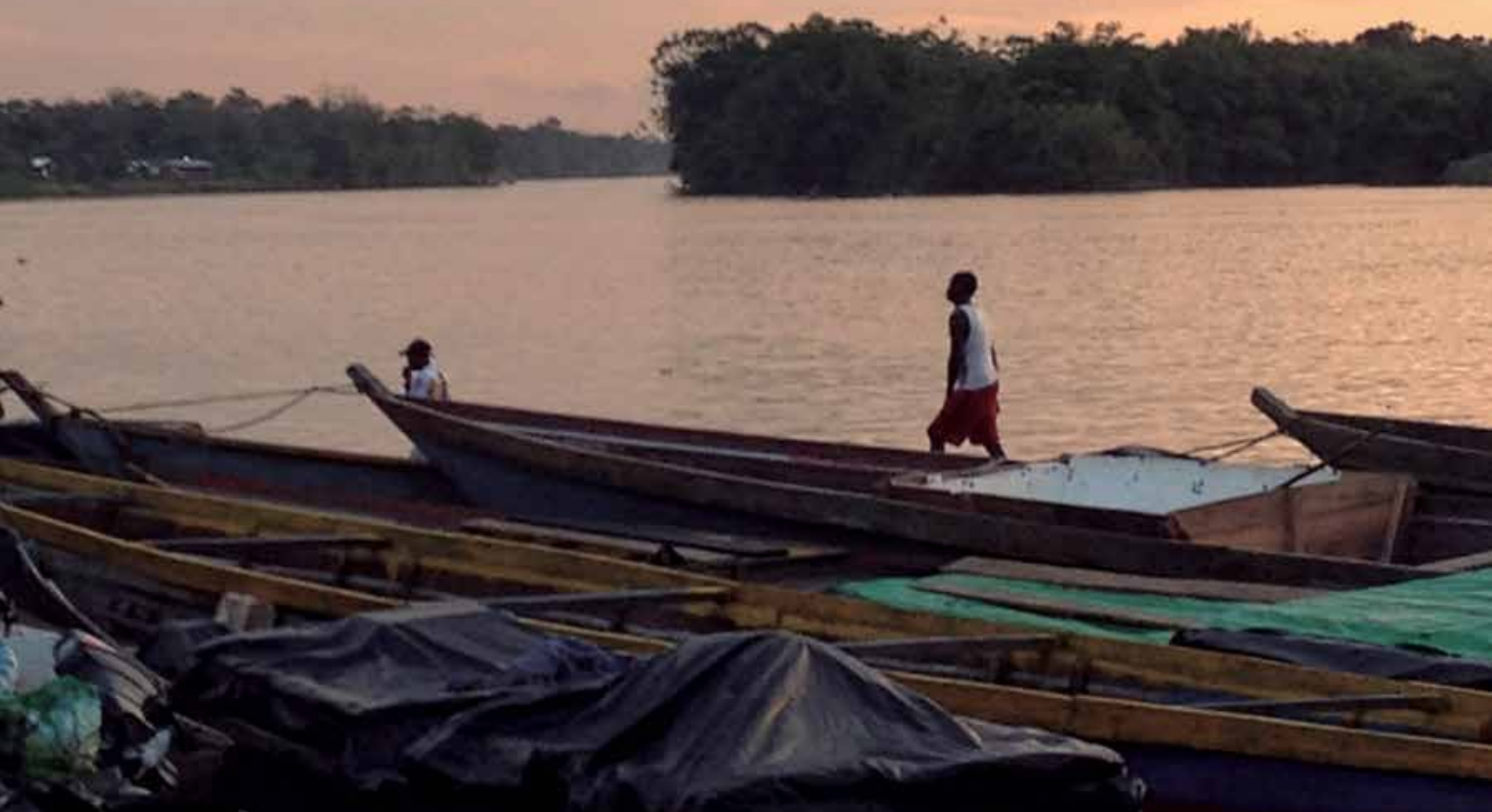
3
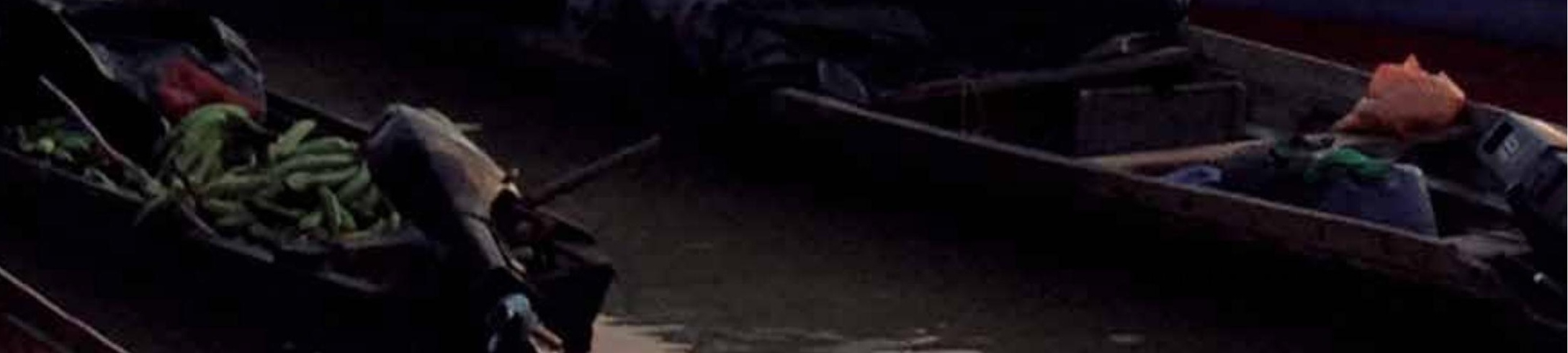


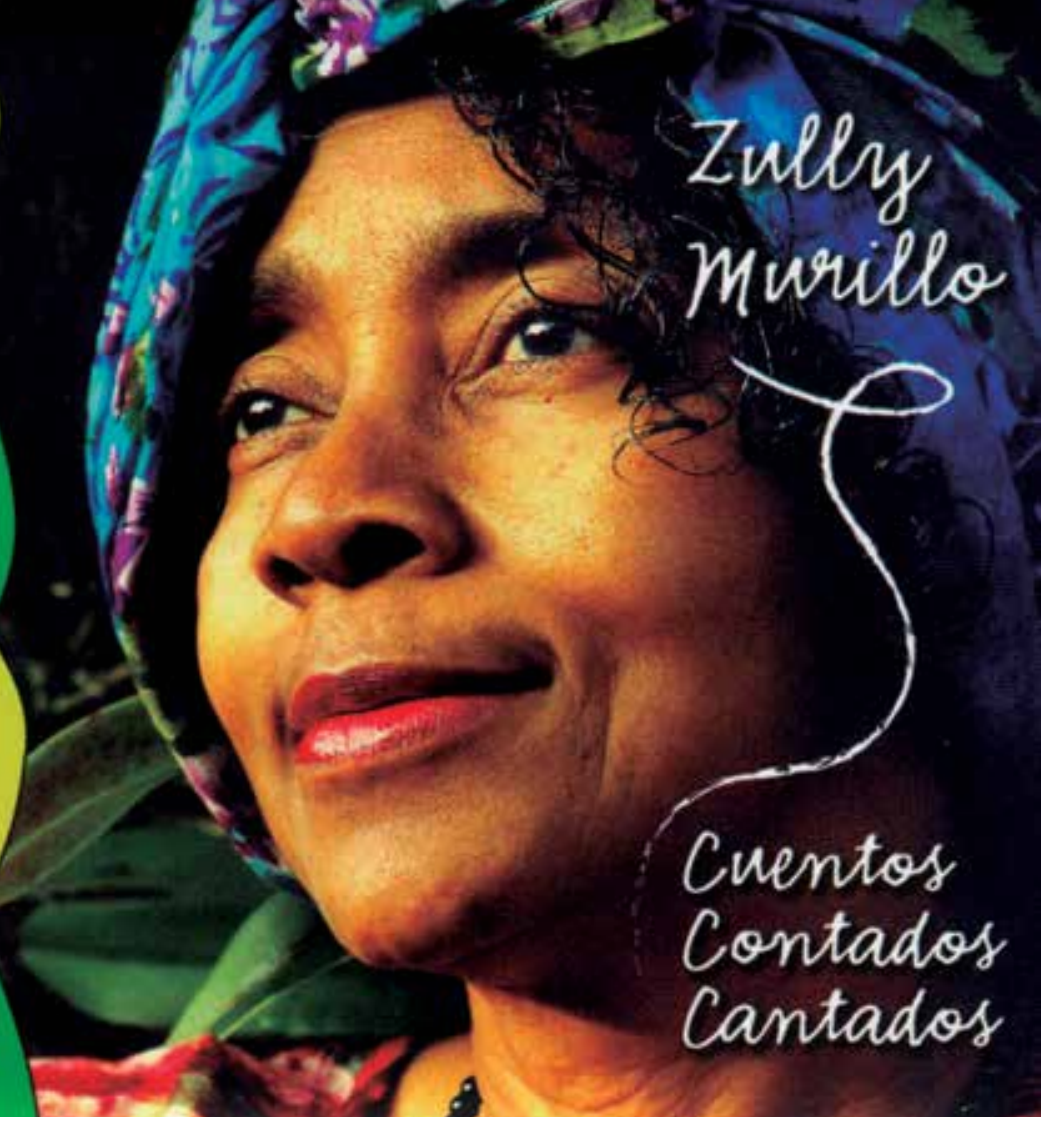

A Cuentos Contados Cantados, 2000. Zully Murillo. Jugando, mamá, jugando Producciones. Cali

volví a Quibdó.

\section{De separaciones y reencuentros}

A: ¿Te casaste muy jovencita?

Z: Ni tan joven. Sino que ya la onda que manejaba el padre de mis hijos, un abogado muy serio que no transigía con las cosas [la música]; estuvo muy bien mientras éramos novios, pero ya después no más: Usted es la esposa, [se dedica a] su casa, a sus hijos, así que Zully tuvo que separarse de la música un montón de rato porque ya él no compartía que yo siguiera en nada de eso, y mi proyecto con el coro, mis canciones fúnebres, mis cantos, esto que es tan espiritual y que a mí me llenaba tanto, tuvo que quedar ahí hasta un tiempo después en que nos separamos. Él se fue.

A: Vos regresás de Bogotá a Quibdó, te vinculás al magisterio, te casás, ¿tus hijos también crecen en Quibdó?

Z: No, aquí en Cali. Nos vinimos cuando el hijo mayor tenía un año, y ya iba a tener el segundo, y aquí nació la tercera, los tres se llevan entre año y año y medio; llegamos extraños a este sitio, no teníamos familia...

\section{A: ¿Por qué vinieron a Cali?}

Z: Porque mi esposo, abogado, se vinculó con la Procuraduría. Él también quería otros horizontes, y fue aquí donde después me vinculé al magisterio, estaba repartida entre mi trabajo y estar en la casa con los chicos, orientar tareas, vigilar, aconsejar, porque no quería que algo tan precioso se me fuera a descarrilar y, gracias a Dios, ahí estaban los chicos bien orientados; no tuvimos problemas con drogadicción ni con malas compañías ni nada de eso, crecieron muy sanos. En la misma jornada en que yo trabajaba ellos estudiaban, así que al medio día cuando yo llegaba a la casa, los recibía del colegio, así que siempre estuvimos juntos. Cuando terminaron su bachillerato, se fueron a la universidad y ahí sí ya los perdí, jaja; entonces empezó a salir todo esto de la composición y comencé a actualizar unas canciones que había dejado truncas en los años 70, a enriquecerlas, y a iniciar el trabajo de reconstrucción de mis vivencias. Vino el momento de hacer, de sacar lo que tenía acumulado, toda esa inquietud de narrar lo que viví en mi niñez, y empecé a escribir algo que ya estaba en mi mente; tenía las melodías y empecé a darle forma a mi primer trabajo musical que se llama Cuentos contados cantados, que son mis vivencias en medio de la gente, y como tengo tan metida en mí la impresión de lo que es el alabao, escribí la canción "Miedo en el monte", que es la historia de cuando la abuela estaba grave y la vamo’a acompañar...

\section{La música, su esencia}

A: Hablemos de la música. Vos, además de esa tradición, ¿qué formación musical tenés? 
Z: En el colegio me tocó una época en donde la música tenía una importancia muy grande. Nosotros entrábamos a los salones cantando. Nos recibían con canciones, y fuera de eso había una hora semanal de canto, y otra que llamaban la hora social en donde cada uno tenía que salir a cantar, dramatizar o recitar; las maestras tenían orientación musical porque sus profesores, después de esa revolución que hubo en la que por primera vez las mujeres negras tuvieron un colegio en dónde estudiar, les dieron la educación más esmerada. Ellas lo que podían enseñar rudimentariamente nos lo enseñaban y despertaban en nosotros el amor por la música, por actuar, por ser artistas. Otra cosa que era muy importante es que en los pueblos llevaban el cine a los parques. ¿Qué se veía en esos cines? Música, películas mexicanas, películas argentinas; esas canciones eran las que cantaba mi mamá, mi papá, y por supuesto que yo las aprendía. Esa parte va incorporada a mi formación musical; en mi colegio teníamos profesores de música que ya habían tenido formación en el conservatorio de la Universidad Nacional de Bogotá. Abraham Rentería era de una familia musical por excelencia. Él nos daba clases de música, nos enseñaba a solfear lo que buenamente podíamos aprender en una hora semanal. Para él yo era su mejor alumna. Teníamos las nociones de solfeo y también él enseñaba a charranguear en la guitarra. Otra influencia muy importante en esos tiempos fue el padre Isaac Rodríguez ${ }^{7}$. Él fue mi profesor de religión y él tenía una empatía con el profesor de música, Abraham Rentería. También tuve una profesora que iba de Cali, Nélida Tilcia Londoño Arce, que había recibido una educación esmerada, y ella sacaba siempre en la semana un rato para ponernos los clásicos, a enseñarnos a oír, lo que ahora llaman apreciación musical. Eso fue lo que yo recibí. El padre Isaac y Abraham se daban el gusto de integrar en un solo coro a todos los colegios de Quibdó. Por ejemplo: Fiesta del maestro, tal colegio respondía por esta voz, este otro por otra voz [...] había era una "sinfonía", la cosa más hermosa en la Catedral de Quibdó, todos los colegios cantando y cada uno haciendo una voz. Naturalmente yo iba con esa semilla y cuando llegué a Bogotá a la universidad, lo primero que hice fue buscar dónde estaba el que enseñaba a cantar, dónde estaba el que montaba los coros.

A: ¿Así que nunca aprendiste a tocar ningún instrumento?

Z: No, no aprendí, mi papá me empezó a decir: 'mija, pa' que aprenda a cantar sus canciones: esto es do, esto es re, mi, fa, sol, y va cantando así, toque como le salga", y me compró una guitarra... Redondeando mi formación musical, puedo decir que yo tenía lo de la parte urbana, lo de la ciudad, sumado a todo lo de las veredas y de Quibdó que era un pueblo. Tenía el universo en mi cabeza, pero ansiaba ir a producir a partir de todo en lo que me había formado y llegué a mi colegio donde me gradué, donde hice la primaria, a esparcir lo que sabía, a formar maestras nuevamente.

Alí le di salida a toda la musicalidad que tenía, más lo que había aprendido en la universidad; allá fui del grupo de coros, del grupo de danzas. Llegué con todas esas inquietudes a mi colegio a formar grupos, a unirme con mis compañeras. Una llegaba de Medellín, otra se había quedado allí, pero íbamos a integrar lo que aprendimos, formábamos un trío y nos íbamos a cantar serenatas a tres voces, a donde nos necesitaban, a celebrar los cumpleaños; luego teníamos salidas con el grupo de nuestras estudiantes y se me ocurrió que también podíamos formar un grupo de coros pero que fueran solamente con cantos fúnebres, con alabaos, romances y todas las canciones de gualíes ${ }^{8}$. Hacia 1969 nos invitaron a Popayán a que en esa Semana Santa presentáramos una muestra de los cánticos a varias voces, entonces integré con mis alumnas y otras profesoras, y con Heriberto Valen$\mathrm{cia}^{9}$, un grupo coral. Fue grandioso para nosotros y también para el público porque fue muy solemne, la gente estaba prendida de lo que cantábamos, y cuando se terminó la presentación y el público ya iba disolviéndose, algunas personas coreaban e iban repitiendo los cánticos que habíamos llevado. Cuando decíamos que este es un Santo [Dios] -que es el canto más solemne y que cuando se canta en el novenario de los muertos la gente se pone de pie-, toda la gente se ponía de pie, nos seguían lo que nosotros estábamos diciendo, y coreaban los estribillos de los alabaos, de los romances y de las salves ${ }^{10} \ldots$

Cuando ya mis hijos crecieron y me hice mayor, independiente, sin esposo, en la casa, hice mucha empatía con los de la colonia de Guapi. Ellos me ponían a cantar, y allá había un señor que tocaba la guitarra, Julián Angulo, quien era feliz acompañándome: "que cantá, cantá más duro" [me decía]. No, porque yo estaba enseñada era a cantar en coro. "Que no, que cantá sola; sacá la voz", y yo decía: "no, no puedo, no quiero, ¿para salir en televisión? Nada. ¿Para entrevistas en radio? Nada." Hasta que yo no sé cómo fue que cuando llegaron los de la orquesta Guayacán que conocieron una de mis canciones: "ah, que la queremos grabar".

7. Isaac Rodríguez Martínez, misionero claretiano español quien llegó a Quibdó hacia 1935 y, desde su ministerio, transformó la vida musical de esta región.

8. Gualí: Ritual de velación de niños muertos menores de siete años.

9. Músico chocoano, formado en el Conservatorio de Música de la Universidad Nacional de Colombia en Bogotá. 10. Salve: Oración entonada a la Virgen María. 
Listo, grábenla. Luego la Contundencia:

"Que queremos grabar tal y tal canción", yo se las daba pa' que la grabaran, pero [me decían:] "no, ahora queremos que vos nos acompañés en la grabación”, y yo: “Ayy, cómo hago, por Dios!” Y ahí entré y canté con ellos, y ahí empecé... me buscaban y me exigían que fuera, que cantara, que sacara la voz. Primero cantaba lo que sabía de todos los demás, y me dijeron: "no, cantá tus canciones" y ahí empecé a cantar las mías.

A: Zully, ¿en qué momento empezaste a hacer parte de grupos y en cuáles estuviste?

Z: ¿Eh? yo no soy de ningún grupo. Cuando hay una presentación, un concierto, casi siempre tengo el grupo que va a acompañarme, y hasta les digo: Hagan sus cosas y me dicen en dónde es, en qué ciudad, a qué horas y cuál es el escenario, y ya, así lo hacemos. Por ejemplo cuando estamos aquí en Cali, a veces Alexis Lozano forma un grupo de amigos que se llama La Timba, y me llaman: Que vamos a Bogotá, que vamos a Medellín, pero el grupo va allá y yo voy a cantar con ellos [sin ensayar previamente]. Me llama Leonidas Valencia, "Hinchao": "vamos a tener una presentación en el [teatro] Jorge Eliécer [Gaitán] de Bogotá, queremos que nos acompañes". Listo, allí estaré. Y voy con ellos. Bambazulú: "Que en la semana Festiafro en Medellín, ¿vas?” ¡Claro que voy! Pero si me toca a mí [organizar unos músicos que me acompañen], llamo a un primo que toca la guitarra que siempre se sabe mis tonos y le digo: Arme el grupo, jaja; porque me di cuenta que esa experiencia de citar a los músicos, ensayar y no sé qué más [es bien difícil], y no falta el que dice que no tiene para el bus, y hay que sacar [dinero] y no, no quiero [saber] nada [de eso], cuando ya esté todo listo, ya sí voy. Y ahora en la vejez, pues sí tengo gente que me dice: "queremos que cante con nosotros": ChocQuibTown, Bambazulú... y yo voy y canto y grabo con ellos. Ahora que me llamaron para los premios Shock me preguntan: "¿y quién es su representante?” Pues yo misma. ¿Empresa? Zully Murillo. Jaja, esa soy yo.

Federico: Si siempre cantás distinto, si nunca cantás igual, ¿cómo hacés para cantar con los coros?

Z: [En tono pícaro responde]: Ese es un problema gravísimo, les cuento esta anécdota. Los chicos de ChocQuibTown están haciendo un trabajo discográfico en el que están enriqueciendo sus éxitos, hemos vuelto a cantar "La calentura" [canta:] "esta es mucha calentura"... Y me dicen: "listo, ahora vas a volver a grabar haciendo la segunda voz", ¿cómo? "yo no sé, usted la va a cantar igual". Ese fue el problema que tuvimos en el disco que grabamos en estudios Niche, y cuando fueron a hacerlo allá en Bogotá, no aparecía nada igual de lo que yo había cantado. Y yo decía: "Ahí, póngamelo a ver cómo es que lo tengo que cantar, a ver... jay!, ¿yo cómo canté eso así? El ritmo era hasta distinto, hice un corte diferente... Me lo tienen que poner otra vez para yo aprendérmelo y ahora sí poderlo grabar, y si me ponen a doblar, lo perdí." De modo que he tomado la decisión de que me esmero en cantar lo mejor que puedo, para que por si acaso ocurre algo, ya quedó grabado. Por ejemplo, el primero de los Cuentos contados cantados fue cantado así, en bloque, derecho.

A: Es un problema pero también es la belleza de estar siempre creando la música, recreándola.

Z: Sí, y ahora, en una canción que hay ahí, en El Bongo, yo no sé cuántas veces la he cantado y todas las veces me sale diferente, eso es una cosa que yo no puedo remediar. Ya estoy entendiendo qué es lo que pasa, es que tengo un problema: como de chica sufrí artrosis, la artrosis está en el esternón y en la clavícula, eso me aprisiona un poco el corazón, entonces tengo una arritmia. El otro día el cardiólogo me puso a escucharlo, y él va así: pum, tu tu, pum, luego se para y... turututututú, y sigue... yo voy cantando según como lo siento, y es que mi corazón va haciendo todo eso.

\section{A: Pero no es solamente el corazón...}

Z: Eso me pasa. Si hacemos una prueba de sonido, canto de una manera, y cuando estamos en la presentación canto de otra. Canto con otra métrica y van otros sonidos, y si me da por meter un disonante y hacer alguna cosa, la hago. Por eso, esos señores que me acompañan ya me conocen y ellos tienen que ir conmigo porque ellos saben que no se pueden perder, que tienen que ir marcando su compás, no importa si yo me salgo de ahí y tomo luego otro, si estiro, si alargo, pero no se pueden poner a tratar de ir cambiando conmigo, ellos saben que tienen que llevar su compás; a mí me dicen: "cante una canción", y yo nunca la canto igual, porque pienso que estamos en una evolución y nunca voy a sentir exactamente [...] lo que sentí en un momento no lo puedo sentir en otro, mi expresión es completamente distinta.

\section{Creación e interpretación, caminos que vienen desde la orilla}

11. Josse Narváez, actor y cantante, nacido en Sahagún (Córdoba) y radicado desde los 5 años en Bogotá. En la interpretación que hace de esta canción Narváez se apropia de técnicas de grabación y tímbrica del reggaetón, con rítmica similar al merengue dominicano y al paseo vallenato; otra cosa sugiere la obra como nos la canta Zully, a capella, en la intimidad de su casa, en la que se intuye una forma de cantar ad libitum, estilo tradicional de los romances y alabaos. 


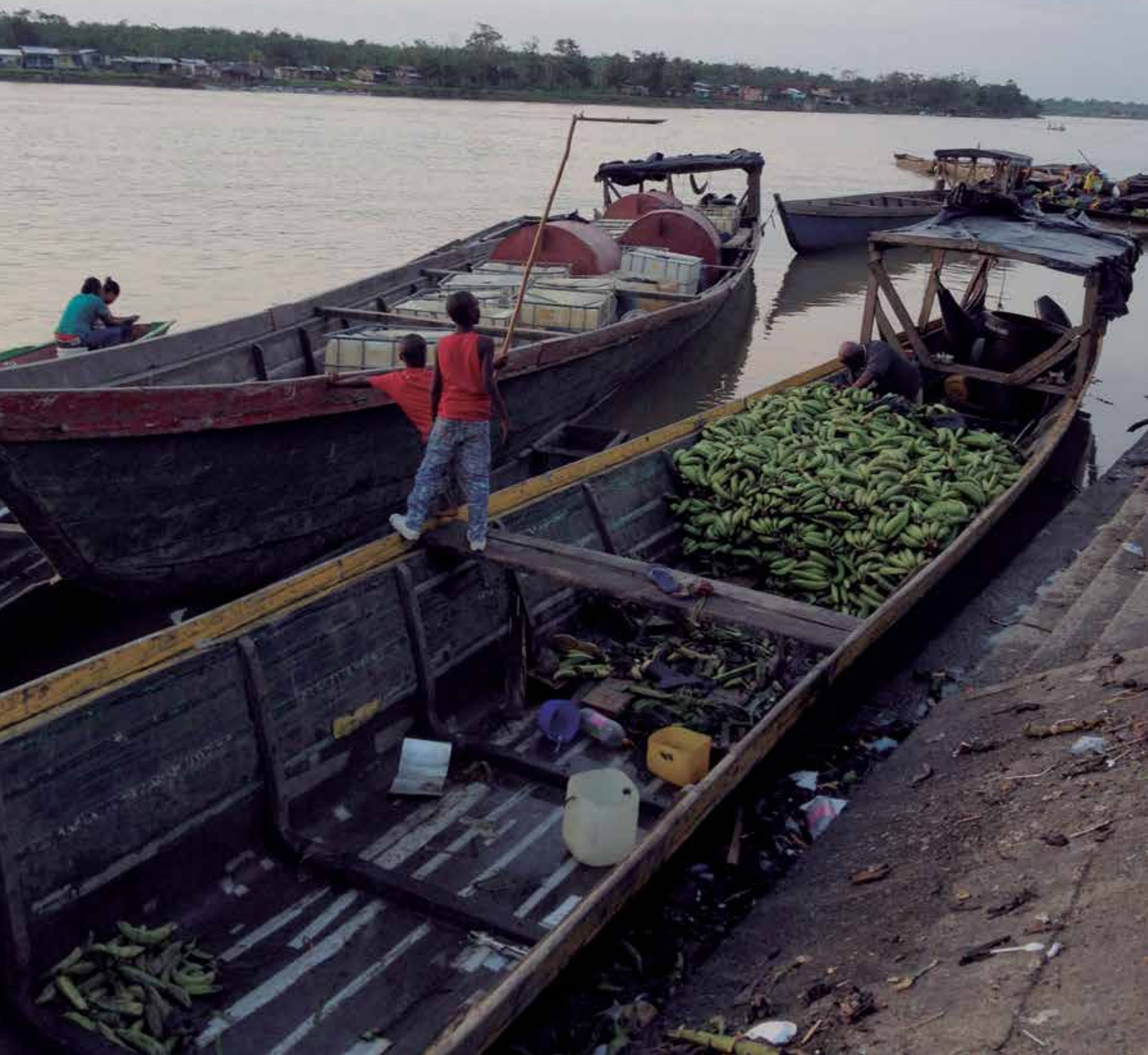


F: ¿Grabaste alguna vez cuando tenías el trío en Quibdó o el grupo coral con el que fuiste a Popayán?

Z: No, porque en esos tiempos era supremamente complicado [...] ¿quién tenía una grabadora? Para tener, por ejemplo, lo de la muestra de Viro Viro ${ }^{14}$, tuvimos que pedir prestada una grabadora, y era con el viejo casete y pilas porque en Viro Viro no había energía eléctrica. En ese entonces eso era muy difícil, pero cómo quisiera que hubiera sido en esta época actual... quien tiene un teléfono ya puede grabar. Todo lo que perdimos y que pudimos haber grabado...

A: Zully, ¿qué géneros musicales, qué ritmos has compuesto? ¿Has trabajado solamente la cultura tradicional del Chocó o has incursionado en otros géneros?

Z: Bueno, yo hago de todo. Sones, boleros, baladas, hasta con cánticos que tienen el deje de los alabaos que son unos lamentos. Por ejemplo..., en un sueño yo pensaba que me iban a enterrar viva, entonces yo desde mi dimensión de muerta estaba cantando y diciendo... cantándole a mi alma, preguntándole a dónde se había ido, que me había dejado el cuerpo: [canta] "¿Alma mía, ¿dónde estás? / alma mía, ¿dónde has ido?/ mi cabeza ya no piensa,/ y no tengo ya latidos, / alma mía, ¿dónde estás?/ alma mía, ¿dónde has ido?/ Que mis pasos ya no avanzan/ y no escuchan mis oídos..." Más o menos voy diciendo qué es lo que ya no hacen: Que mis manos ya no sienten, que mi piel ya no lo siente y no tengo ya sentidos, por eso ahí está presente el lamento del alabao que perfectamente encajaría y si hubiera algo religioso ahí, esa sería la musicalidad de un alabao.

A: ¿A qué le cantás, Zully?

Z: ¡Ah!, buena pregunta, aquí dice: [canta] "A mí las canciones/ me brotan del alma, / como de una noche/ sigue una mañana,/ como una semilla/ origina una planta, / así como un hijo/ brota de la entraña./ Ellas se alimentan/ de mi fantasía,/ de mi sufrimiento,/ de mis alegrías,/ ya de mis angustias, / ya de mi optimismo,/ ya de mi pesar/ o de melancolía./ Ricas en nostalgias, / ricas en perdones, / ricas en vivencias, / ricas en amores,/ de amores de amantes, / y de anocheceres, / de amores de esposos/y de amaneceres,/ de amores que van,/ de amores que vienen,/ de amores que nacen,/ de amores que mueren,/ amores perdidos, / amores ganados, / amores de padres,/ amores de hijos, / amores de hermanos, / amores de amigos, / ya recuperados, / ya reconstruidos, /

\section{Atrato. Fotografía: Alejandro Tobón}

y cuando las canto/ ya me siento en calma, / porque todas ellas/ me brotan del alma."15

A: Esa es la respuesta perfecta. Hablemos de tus producciones musicales, ahorita nos contabas que tenías tres discos.

Z: Tres y otros que van ahí en crudo. Primero salió Cuentos contados cantados, que resistió una primera edición, y sacamos la segunda edición ya con el material gráfico mejorado. El sonido lo pusimos más moderno, y se masterizó. Luego hice Los pregones de mi tierra, pensando en los niños de aquel tiempo y en las cosas que nos decían: Que no podíamos jugar con la sombra porque era malo, y un montón de vainas así; y luego un disco ya más maduro pensando en el género femenino, Ella, otro cuento, porque la mujer es un cuento aparte. Empieza con una canción de cuna que compuse que se llama "Dormite" y que ahora también canta Marta Gómez ${ }^{16}$. Alli va incluida porque tenía que ir la faceta de la mamá que arrulla; está también la mujer que reclama al irresponsable que la deja criando a un hijo sola; está la que es maltratada, enseñándole a que no se deje joder; están dos canciones a la tierra: "Mi tierra natal" y "Tierra del alma"; una para una señora anciana que quiere vivir en medio de sus recuerdos: "hoy vienen los muchachos/ a arreglarme la casa, / disque a acomodarme;/ dicen que hay mucho chéchere,/ mucha cosa vieja, /quieren modernizarme...", pero ahí empieza la vivencia de ella que dice que no le vayan a tocar su machetico, que no le cojan su calabazo; sigue la canción con la abuela contando la historia de cuando morían godos y liberales, el comienzo del siglo XX ["Mis recuerdos"]; y para no dejar los cuentos está un diálogo entre una culebra y una lombriz; está el canto a la niñita morena; el canto de la maestra que perdió el amor, que se le fue y que se sienta en la playa con sus alumnos supuestamente disque a ver las olitas, pero es con la esperanza de verlo volver, y así... También tengo en estudio con Tino Herrera, unas canciones que yo digo que son de tinte infantil. Hay una canción en particular que la hice a propósito, conservando la esencia del romance: [canta] Vení sentate a mi lao/ te voy a decí una cosa/ jay! hombe, jay! hombe/ jay! hombe, manita, jay! hombe./ Ayer barriendo la casa/ hallé una joya preciosa, / jay! hombe, jay! hombe,/ jay! hombe, manita, jay! hombe"; entonces viene el diálogo en el que se dice cómo es la joya que encontró, que fue que barriendo la

15. Esta canción, autoría de Zully, se titula "De amores", y saldrá en su próximo disco compacto Son de amores.

16. Marta Gómez la incluyó en su repertorio. Ellas la cantaron juntas, en compañía de Hugo Candelario González en un concierto realizado en Cali en el año 2012 para Telepacífico. Se puede ver esta canción en Youtube: "Dormite - Zully Murillo / Marta Gómez", o el documental completo: "Marta Gómez, Cantautora - (Documental)". 
pudieron estudiar, nosotras teníamos que tomar la bandera de que con la ciencia, con el saber, con la educación era como ascendíamos, porque la ignorancia nos llevaba otra vez a la esclavitud y a la sumisión. Mi mamá fue maestra y casi todos en ese tiempo mandaban a sus hijas a que fueran también maestras, porque había que esparcir la semilla del saber, y había que profesionalizarse, y había, sobre todo, qué tener una carrera que pudiera servir para el sostén de los hijos. [En el Caribe] les llegó el comercio. A ellos no les tocó la dureza que nos tocó a nosotros, que éramos esclavos y de la noche a la mañana... "Sí, tienen libertad, pero ¿cómo van a sobrevivir? Tienen que seguir trabajando para nosotros, ganarse la comida". ¿A qué gente negra le hicieron un préstamo? ¿Quién confiaba para darles un crédito? Estaba la pobreza, y continuó la sumisión al tener que seguir trabajando para los patronos, para los esclavizadores.

A: Simplemente se cambió la estructura de la esclavitud.

Z: Sí. Y hasta el día de hoy eso es. No tenemos una clase económica pudiente, ninguna.

\section{A: Cómo que no... La clase política.}

Después de compartir dos días completos de trabajo, de cantarnos más de 50 romances, de encontrarle la música a diversos textos tradicionales que le llevamos, de conocer que es vegetariana, que su cabello está lleno de rastas, que conserva la lozanía de juventud y una voz primaveral, Zully Murillo nos deja claro, como al inicio de esta entrevista, que el tiempo que vivimos no es más que un intervalo de eternidad en el que nos seguimos encajando. Ojalá Colombia sintiera que canta a través de la voz de Zully... intervalo de eternidad.

\section{Referencias}

Caicedo Licona, Carlos Arturo (2004). Isaac Rodríguez Martínez. Servidor silencioso del pueblo afrochocoano. (Misioneros claretianos - Colombia occidental). Quibdó: Colección ayer y hoy en nuestra historia.

González Escobar, Luis Fernando (1997). "Sirio libaneses en el Chocó. Cien años de presencia económica y cultural”. En: Boletín Cultural y Bibliográfico, Vol. 34, No. 44. Bogotá: Banco de la República.

Molano, Adriana, Andrea Restrepo y Mateo Molano (2009). Cantos de desarraigo. Travesías de la Costa Pacífica a Bogotá. Madrid: Fundación Contamíname para el Mestizaje Cultural y la Agencia Española de Cooperación Internacional para el Desarrollo.

Sierra García, Jaime (1995). Diccionario Folklórico de Antioquia. Medellín: Universidad de Antioquia.

Tobón Restrepo, Alejandro (2012). Relatos cantados de la vida y de la muerte. Apropiación y transformación de los romances en la cultura de la cuenca del río Atrato, Colombia (tesis doctoral). Sevilla: Universidad Pablo de Olavide.

Tobón Restrepo, Alejandro, María Eugenia Londoño Fernández y Jesús Zapata Builes (2006). Entre sones y abozaos: Aproximación etnomusicológica a la obra de tres músicos de la tradición popular chocoana. Medellín: Universidad de Antioquia, Premio Nacional de Cultura.

\section{Discografía}

Murillo Zully (2000) ${ }^{18}$. Cuentos Contados Cantados. Cali: Jugando, Mamá, Jugando Producciones.

Los pregones de mi tierra (2009). Cali: Zully Murillo Producciones.

Ella, otro cuento (2012). Cali: Jugando, Mamá, Jugando Producciones.

Valencia, Leonidas (director) y Ana María Arango (textos) (2009). Catiá catiadora. Cantos de río y selva. Repertorio de música vocal del Pacífico norte colombiano. Bogotá: Ministerio de Cultura - Asinch.

\section{Páginas web}

http://quibdoeducativa.wordpress.com

www.jossenarvaez.com

www.zullymurillo.com

http://www.youtube.com/watch?v=oEdyMzJbMUI (Salsa Passion. Alfredo de la Fe. Canción: Ya no te estoy creyendo]

www.mamajuliamusic.com

www.chocquibtown.com

http://www.youtube.com/watch?v=LuQzuz-GPKg (Documental de Marta Gómez, cantautora) 